\title{
Power Absorption analysis of Coconut Oil in a Microwave Oven with various parameters.
}

\author{
Smitha I.S \\ Dept of EIE, \\ FISAT, Kerala.
}

\author{
Juno Devassy \\ Dept of EIE, \\ FISAT, Kerala.
}

\author{
Akhil Gopalakrishnan \\ Dept of EIE, \\ FISAT, Kerala.
}

\author{
K. Rajeevkumar \\ Dept of Instrumentation, \\ CUSAT, Kerala.
}

\begin{abstract}
For the study of $\mathrm{ZnO}$ thin film deposition using a low cost microwave plasma deposition unit, $a$ detailed analysis is required to ensure that sufficient power is delivered to plasma chamber. Hence a power analysis was carried out to observe the power absorbed by different loads when it is heated using a microwave oven. Here the load used is coconut oil, which is one of the most common edible oils. The power absorption characteristics of this load is observed and plotted by varying different parameters like time, volume and magnetron voltage. The same analysis is done with water, so that it can be taken as a reference. The power absorbed by water was higher when it is compared to coconut oil in all cases with different parameters. The results show the comparison of thermal properties and heating characteristics of coconut oil and water when they have undergone microwave radiation.
\end{abstract}

\section{General Terms}

Absorbed power, Magnetron input voltage, Microwave oven.

\section{INTRODUCTION}

The microwave plasma deposition method for the preparation of thin film is a chemical deposition method. The only load to the microwave emitter [Magnetron] is the gas that is needed to be ionized. Initially the gas in the plasma chamber is evacuated and very few molecules are left behind the chamber. When microwaves are bombarded on these molecules of air under low pressure they ionize to give a plasma state, suitable for film preparation. Hence substantial power should be delivered to the chamber to keep the gas ionized and help keep up the state. So to ensure that required power is delivered we need to perform a power analysis of the microwave equipment.

The power analysis can be done by the calorimetric analysis of a heating load and then observing the thermal characteristics. The load could be any material commonly subjected to microwave application (like cooking) e.g. edible oil etc. we have taken coconut oil as the load.

The frequency ranges of microwave though not precisely defined the usual values in accordance with the industrial, scientific and medical[ISM] frequency bands for noncommunication purposes we employ $2.45 \mathrm{GHz}$ for food applications $_{[1]}$.

The electrical properties of coconut oils are close to those of conventional insulating fluids. Coconut oil based lubricants offer significant environmental benefits with respect to resource renewability, load toxicity and provide satisfactory performance in the wide array of applications. Coconut oil could be an appropriated response to environmental safety and health problems and could also reduce the exploitation cost of mechanical parts. On the other hand, they are known to possess low thermal, oxidative and hydrolytic stabilities and poor low temperature characteristics ${ }_{[2]}$.

Like all other typical heating methods, in microwave too the rate of heating is directly proportional to the microwave power, i.e. for a high value of power a higher change from initial temperature is observed.

The study was conducted by following the International Standards set by IEC 705(1988) [3]. This standard gives a relation between microwave power applied and increase of temperature in loads, as

$P=\frac{\Delta T * V * C * \rho}{t}$

Where,

P- Microwave power used for heating in watts.

V - Volume of load in $\mathrm{mL}$

C- Specific heat capacity in $\mathrm{kJ} / \mathrm{kgK}$

$\rho$-Density of the fluid in $\mathrm{kg} / \mathrm{m}^{3}$

$\mathbf{t}$ - Time of heating(s)

$\Delta T$ - Mean temperature rise $(\mathrm{K})$

\section{REQUISITES AND PROCEDURE}

- Microwave oven (Whirlpool Magic Cook 20S, $2.45 \mathrm{GHz}$ microwave oven, Supply voltage: $230 \mathrm{~V} / 50 \mathrm{~Hz}$, Rated input: 1100W, Rated output:750W, Cavity volume: 20L, Cavity dimensions: 196mm*292mm*295mm)

- Autotransformer, Thermometer, Borosil glass beaker (Weight -90.753g), Stop watch.

- Coconut oil (Roasted onamvelichenna, micro filtered pure coconut oil, edible grade).

- Demineralised water.

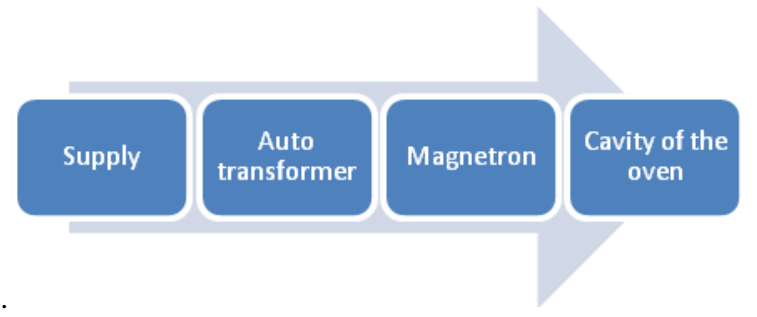

Fig1: shows the block diagram of the microwave oven. 


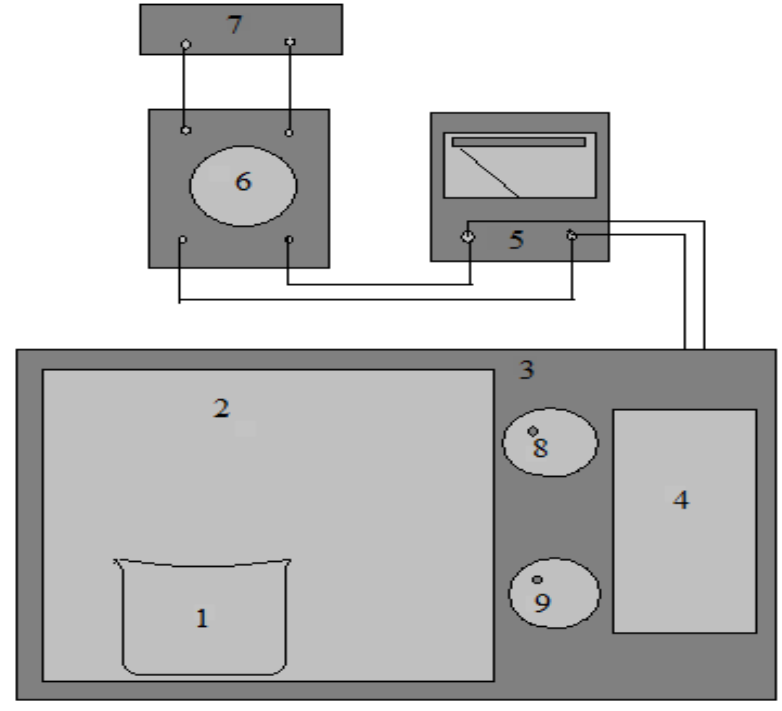

Fig2: shows the experimental setup of the microwave

1. Beaker. oven.

3. Whirlpool Microwave oven.4. Magnetron.

5. Voltmeter.

6. Autotransformer.

7. Power supply.

8. Power adjustment.

9. Timer.

The autotransformer is used to supply the desired input voltage, from the supply voltage $(230 \mathrm{~V})$, to the magnetron. The input voltage is shown by the voltmeter. The magnetron now produces microwaves, which is used by the beaker to absorb heat.

\subsection{Procedure for calorimetric power analysis.}

Take V ml of oil in a beaker. Stir it for 20 seconds. Record the initial temperature of the oil using a thermometer, which is calibrated in centigrade. The direct incorporation of thermocouple in measuring the temperature inside the microwave oven's cavity is avoided as thermocouple induces intense electric fields which cause sparking in the presence of microwave energy. Therefore, it is also not possible to take insitu measurements ${ }_{[6]}$. Place the beaker containing the oil in the microwave oven at the centre position. Keep the maximum power of microwave oven as $550 \mathrm{~W}$. Now switch on the power supply. Adjust the autotransformer to $230 \mathrm{~V}$. Switch on the microwave oven. Heat the oil for' $t$ ' seconds keeping the required parameter constant. After't' seconds, the oven is switched off and the final temperature is recorded without any time delay. Take 5 readings for the same to ensure the repeatability of the readings. After each reading, the chamber is given 20 seconds of warm up time. Repeat the process for varying magnetron voltages and volume too by keeping the required parameters constant.

The output power is determined by the equation

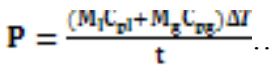

Where,

$\mathbf{M}_{\mathbf{l}}$ and $\mathbf{M}_{\mathbf{g}_{-}}$mass of the fluid and the beaker respectively.

$\mathbf{C}_{\mathbf{p l}}$ and $\mathbf{C}_{\mathbf{p g}}$ - specific heats of the fluid and beaker respectively.
$\Delta \mathbf{T}$ - rise in temperature.

t- Time of heating in seconds.

\subsection{Procedure to find out $\mathbf{M}_{\mathbf{l}}$.}

1. Measure $\mathrm{M}_{\mathrm{g}}$, by weighing an empty beaker using a sensitive weighing balance with an accuracy of $0.001 \mathrm{~g}$.

2. Weigh the beaker with $100 \mathrm{ml}$ of load in it. The current reading gives the value of $\left(\mathrm{M}_{1}+\mathrm{M}_{\mathrm{g}}\right)$.

3. Subtracting the value of $\mathrm{M}_{\mathrm{g}}$ obtained from step1, from the value of $\left(\mathrm{M}_{\mathrm{l}}+\mathrm{M}_{\mathrm{g}}\right)$ obtained from step2 gives the weight of $100 \mathrm{ml}$ of the load, i.e.

$$
\left(\mathrm{M}_{\mathrm{l}}+\mathrm{M}_{\mathrm{g}}\right)-\mathrm{M}_{\mathrm{g}}=\mathrm{M}_{\mathrm{l}}
$$

\section{ANALYSIS AND RESULTS}

The average power absorbed by coconut oil for various parameters were calculated. Magnetron input voltage at $230 \mathrm{~V}$; $50 \mathrm{Hzwas}$ set by the autotransformer. Power absorbed was calculated using the IEC 705 formula.

\subsection{Power absorbed by coconut oil for varying time periods at volume $(50 \mathrm{ml})$, and magnetron input voltage $230 \mathrm{~V}$.}

Mass of $50 \mathrm{ml}$ of coconut oil $\left(\mathrm{M}_{\mathrm{l}}\right)=43.203 \mathrm{~g}$

Specific heat of coconut oil $\left(\mathrm{C}_{\mathrm{Pl}}\right)=1.67 \mathrm{~kJ} / \mathrm{kgK}$

Mass of beaker $(\mathrm{Mg})=43.203 \mathrm{~g}$

Specific heat of beaker $\left(\mathrm{C}_{\mathrm{pg}}\right)=1.67 \mathrm{~kJ} / \mathrm{kgK}$

Table1. Power analysis of $50 \mathrm{ml}$ of coconut oil as load at $230 \mathrm{~V}$ with heating time, $t=60$ seconds.

\begin{tabular}{|c|c|c|c|c|}
\hline $\begin{array}{c}\text { S1 } \\
\text { no. }\end{array}$ & $\begin{array}{c}\text { initial temp } \\
(\mathrm{C})\end{array}$ & final temp (C) & $\begin{array}{c}\Delta \mathrm{T} \\
(\mathrm{C})\end{array}$ & $\begin{array}{c}\text { power in } \\
\text { watts }\end{array}$ \\
\hline 1 & 31 & 72.5 & 41.5 & 96.353 \\
\hline 2 & 31 & 73.5 & 42.5 & 98.675 \\
\hline 3 & 31 & 74 & 43 & 99.836 \\
\hline 4 & 31 & 77 & 46 & 106.8 \\
\hline 5 & 31 & 75 & 44 & 102.16 \\
\hline & \multicolumn{3}{|c|}{ Average Power } & $\mathbf{1 0 0 . 7 7}$ \\
\hline
\end{tabular}

Table 2. Power analysis of $50 \mathrm{ml}$ of coconut oil as load at $230 \mathrm{~V}$ with heating time, $\mathrm{t}=90$ seconds.

\begin{tabular}{|c|c|c|c|c|}
\hline Sl no. & $\begin{array}{l}\text { initial temp } \\
\text { (C) }\end{array}$ & $\begin{array}{l}\text { final Temp } \\
\text { (C) }\end{array}$ & $\begin{array}{l}\Delta \mathrm{T} \\
(\mathrm{C})\end{array}$ & $\begin{array}{c}\text { power in } \\
\text { watts }\end{array}$ \\
\hline 1 & 31 & 81 & 50 & 77.392 \\
\hline 2 & 31 & 82 & 51 & 78.94 \\
\hline 3 & 31 & 81 & 50 & 77.392 \\
\hline 4 & 31 & 84 & 53 & 82.036 \\
\hline 5 & 31 & 82 & 51 & 78.94 \\
\hline & & \multicolumn{2}{|c|}{ Average Power } & 78.94 \\
\hline
\end{tabular}


Table 3. Power analysis of $50 \mathrm{ml}$ of coconut oil as load at $230 \mathrm{~V}$ with heating time, $t=120$ seconds.

\begin{tabular}{|c|c|c|c|c|}
\hline Sl no. & $\begin{array}{c}\text { initial temp } \\
(\mathrm{C})\end{array}$ & $\begin{array}{c}\text { final temp } \\
(\mathrm{C})\end{array}$ & $\Delta \mathrm{T}(\mathrm{C})$ & $\begin{array}{c}\text { power in } \\
\text { watts }\end{array}$ \\
\hline 1 & 31 & 96 & 65 & 75.458 \\
\hline 2 & 31 & 89.5 & 58.5 & 67.912 \\
\hline 3 & 31 & 93 & 62 & 71.975 \\
\hline 4 & 31 & 92 & 61 & 70.814 \\
\hline 5 & 31 & 92.5 & 61.5 & 71.394 \\
\hline & \multicolumn{3}{|c|}{ Average Power } & $\mathbf{7 1 . 5 1 1}$ \\
\hline
\end{tabular}

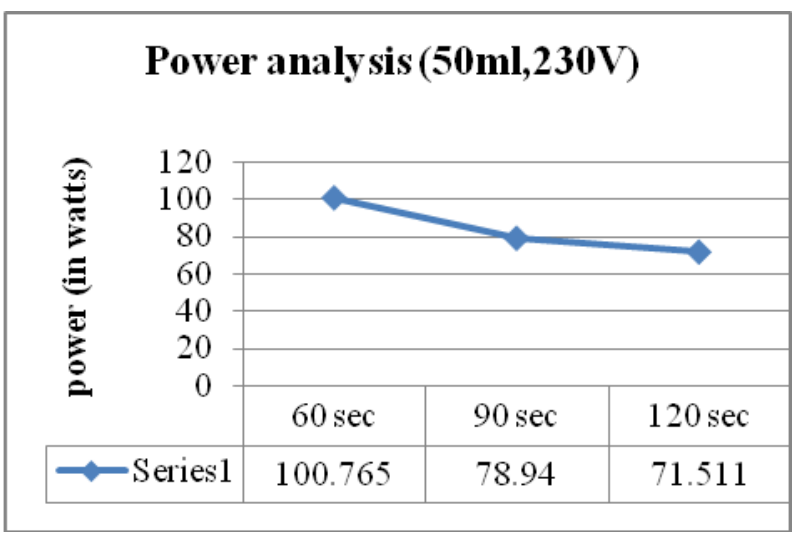

Fig3: shows the average power analysis graph for coconut oil $(50 \mathrm{ml})$ at $230 \mathrm{~V}$ with variable time periods.

3.2 Power absorbed by coconut oil for varying volume at time 60 seconds, and magnetron input voltage $230 \mathrm{~V}$.

Weight of $50 \mathrm{ml}$ of coconut oil $\left(\mathrm{M}_{11}\right)-43.203 \mathrm{~g}$

Weight of $100 \mathrm{ml}$ of coconut oil $\left(\mathrm{M}_{12}\right)-86.406 \mathrm{~g}$

Weight of $150 \mathrm{ml}$ of coconut oil $\left(\mathrm{M}_{13}\right)-129.609 \mathrm{~g}$

Specific heat of coconut oil $\left(\mathrm{C}_{\mathrm{pl}}\right)-1.67 \mathrm{KJ} / \mathrm{kgK}$

Table4. Power analysis of $\mathbf{5 0} \mathbf{m l}\left(\mathbf{M}_{11}\right)$ of coconut oil as load at $230 \mathrm{~V}$ with heating time, $\mathrm{t}=60$ seconds.

\begin{tabular}{|c|c|c|c|c|}
\hline $\begin{array}{l}\text { Sl } \\
\text { no. }\end{array}$ & $\begin{array}{c}\text { initial } \\
\text { temp }(\mathrm{C})\end{array}$ & $\begin{array}{l}\text { final temp } \\
\text { (C) }\end{array}$ & $\Delta \mathrm{T}(\mathrm{C})$ & $\begin{array}{c}\text { power in } \\
\text { watts }\end{array}$ \\
\hline 1 & 31 & 72.5 & 41.5 & 96.353 \\
\hline 2 & 31 & 73.5 & 42.5 & 98.675 \\
\hline 3 & 31 & 74 & 43 & 99.836 \\
\hline 4 & 31 & 77 & 46 & 106.8 \\
\hline 5 & 31 & 75 & 44 & 102.16 \\
\hline & & \multicolumn{2}{|c|}{ Average Power } & 100.77 \\
\hline
\end{tabular}

Table5. Power analysis of $100 \mathrm{ml}\left(\mathrm{M}_{12}\right)$ of coconut oil as load at 230 Vwith heating time, $t=60$ seconds.

\begin{tabular}{|c|c|c|c|c|}
\hline $\begin{array}{c}\text { Sl } \\
\text { no. }\end{array}$ & $\begin{array}{c}\text { initial } \\
\text { temp }(\mathrm{C})\end{array}$ & $\begin{array}{c}\text { final temp } \\
(\mathrm{C})\end{array}$ & $\Delta \mathrm{T}(\mathrm{C})$ & $\begin{array}{c}\text { power in } \\
\text { watts }\end{array}$ \\
\hline 1 & 31 & 67 & 36 & 126.87 \\
\hline 2 & 31 & 65 & 34 & 119.83 \\
\hline 3 & 31 & 66.5 & 35.5 & 125.11 \\
\hline 4 & 31 & 65 & 34 & 119.83 \\
\hline 5 & 31 & 66 & 35 & 123.35 \\
\hline & \multicolumn{3}{|c|}{ Average Power } & $\mathbf{1 2 3}$ \\
\hline
\end{tabular}

Table6. Power analysis of $150 \mathrm{ml}\left(\mathrm{M}_{13}\right)$ of coconut oil as load at $230 \mathrm{~V}$ with heating time, $t=60$ seconds.

\begin{tabular}{|c|c|c|c|c|}
\hline $\begin{array}{c}\text { Sl } \\
\text { no. }\end{array}$ & $\begin{array}{c}\text { initial temp } \\
(\mathrm{C})\end{array}$ & $\begin{array}{c}\text { final temp } \\
(\mathrm{C})\end{array}$ & $\Delta \mathrm{T}(\mathrm{C})$ & $\begin{array}{c}\text { power in } \\
\text { watts }\end{array}$ \\
\hline 1 & 31 & 60 & 29 & 137.08 \\
\hline 2 & 31 & 60 & 29 & 137.08 \\
\hline 3 & 31 & 61 & 30 & 141.8 \\
\hline 4 & 31 & 63 & 32 & 151.26 \\
\hline 5 & 31 & 60 & 29 & 137.08 \\
\hline & \multicolumn{5}{|c|}{ Average Power } & $\mathbf{1 4 0 . 8 6}$ \\
\hline
\end{tabular}

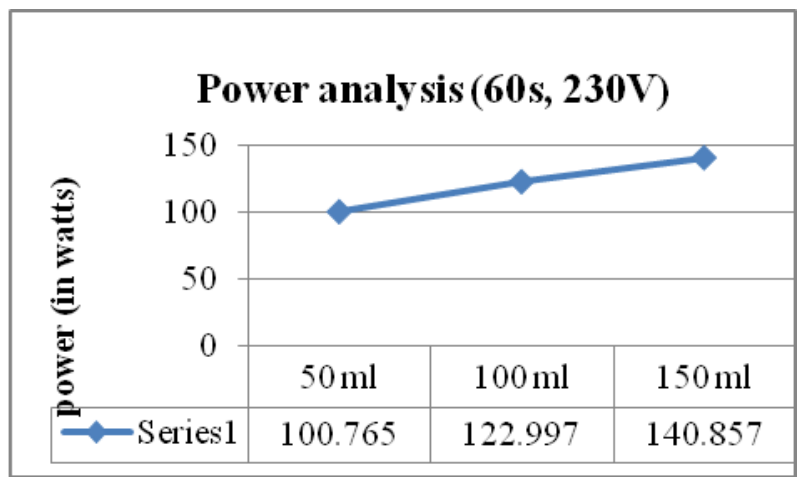

Fig 4: shows the average power analysis graph for coconut oil for 60 seconds at 230 Vwith variable volume.

3.3 Power absorbed by coconut oil for varying magnetron voltages at time 60 seconds and volume $100 \mathrm{ml}$.

Weight of $100 \mathrm{ml}$ of coconut oil $\left(\mathrm{M}_{1}\right)-86.406 \mathrm{~g}$

Specific heat of coconut oil $\left(\mathrm{C}_{\mathrm{pl}}\right)-1.67 \mathrm{KJ} / \mathrm{kgK}$ 
Table7. Power analysis of $100 \mathrm{ml}$ of coconut oil as load with heating time, $t=60$ seconds at $180 \mathrm{~V}$.

\begin{tabular}{|c|c|c|c|c|}
\hline $\begin{array}{l}\text { Sl } \\
\text { no. }\end{array}$ & $\begin{array}{l}\text { initial temp } \\
\text { (C) }\end{array}$ & $\begin{array}{l}\text { final temp } \\
\text { (C) }\end{array}$ & $\Delta \mathrm{T}(\mathrm{C})$ & $\begin{array}{c}\text { power in } \\
\text { watts }\end{array}$ \\
\hline 1 & 31 & 48.5 & 17.5 & 61.674 \\
\hline 2 & 31 & 50 & 19 & 66.961 \\
\hline 3 & 31 & 51 & 20 & 70.485 \\
\hline 4 & 31 & 51 & 20 & 70.485 \\
\hline 5 & 31 & 50 & 19 & 66.961 \\
\hline & & \multicolumn{2}{|c|}{ Average Power } & 67.313 \\
\hline
\end{tabular}

Table8. Power analysis of $100 \mathrm{ml}$ of coconut oil as load with heating time, $t=60$ secondsat $200 \mathrm{~V}$.

\begin{tabular}{|c|c|c|c|c|}
\hline $\begin{array}{c}\text { Sl } \\
\text { no. }\end{array}$ & initial temp (C) & $\begin{array}{c}\text { final temp } \\
(\mathrm{C})\end{array}$ & $\begin{array}{c}\Delta \mathrm{T} \\
(\mathrm{C})\end{array}$ & $\begin{array}{c}\text { power in } \\
\text { watts }\end{array}$ \\
\hline 1 & 31 & 63 & 32 & 112.78 \\
\hline 2 & 31 & 62 & 31 & 109.25 \\
\hline 3 & 31 & 61 & 30 & 105.73 \\
\hline 4 & 31 & 61 & 30 & 105.73 \\
\hline 5 & 31 & 62 & 31 & 109.25 \\
\hline & \multicolumn{3}{|c|}{ Average Power } & $\mathbf{1 0 8 . 5 5}$ \\
\hline
\end{tabular}

Table9. Power analysis of $100 \mathrm{ml}$ of coconut oil as load with heating time, $t=60$ secondsat $220 \mathrm{~V}$.

\begin{tabular}{|c|c|c|c|c|}
\hline $\begin{array}{l}\text { Sl } \\
\text { no. }\end{array}$ & initial temp $(\mathrm{C})$ & final temp (C) & $\begin{array}{l}\Delta \mathrm{T} \\
(\mathrm{C})\end{array}$ & $\begin{array}{c}\text { power in } \\
\text { watts }\end{array}$ \\
\hline 1 & 31 & 66 & 35 & 123.35 \\
\hline 2 & 31 & 68 & 37 & 130.4 \\
\hline 3 & 31 & 66 & 35 & 123.35 \\
\hline 4 & 31 & 66 & 35 & 123.35 \\
\hline 5 & 31 & 67 & 36 & 126.87 \\
\hline & & \multicolumn{2}{|c|}{ Average Power } & 125.46 \\
\hline
\end{tabular}

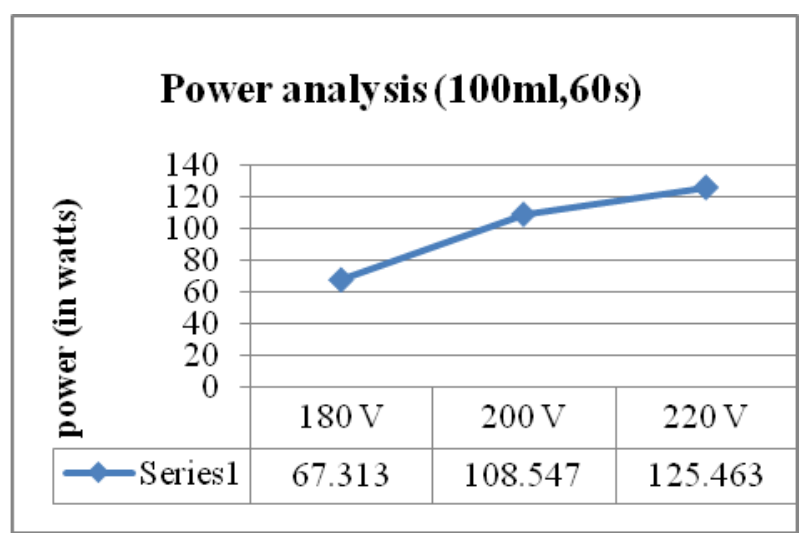

Fig5: shows the average power analysis graph for coconut with variable magnetron voltages.

Vegetable oil basically consists of tri-glycerides, tri-alcohol, called glycerol, with three fatty acids. The fatty acids are composed of linear hydro carbon chains ended by a carboxylic function. These molecules have an even number of carbon atoms and the chain can be saturated or mainly mono, di- and tri- unsaturated.

Coconut oil consists of lower chain saturated fatty acids, known as medium chain fatty acids (MCT). Its metabolism is different from that of normal long chain fatty acids. Medium chain tri-glycerides (MCTs) are aclass of lipids in which three saturated fats are bound to a glycerol backbone. MCTs are distinguished from other tri-glycerides in the fact that each fat molecule is between 6 and 12 carbons in length. MCTs have a different pattern of absorption and utilization than long chain tri-glycerides. Vegetable oils have a tendency to form macro crystalline structure at low temperature through uniform stacking of 'bend' tri-glycerol backbone. Such macro crystals restrict the easy flow of the system due to loss of kinetic energy of individual molecules during self-stacking. The predominantly saturated fatty acid content of coconut oil compounds the problem further. This is attributed to the medium chain tri-glyceride structure of coconut oil which is different from long chain structure of other vegetable oil. During heating process these chain distance increases, so the power absorbed increases. Thus the coconut oil absorbs more amount of power compared to that of other vegetable oils, without getting decomposed, since it consists of medium chain tri-glycerides ${ }_{[2]}$.

Microwave irradiation increases initial reaction rate, compared to conventional heating. This is due to heat transfer by di-polar rotation and ionic conduction in regular alternating microwave field. The apparent activation energy $\left(E_{a}\right)$ of enzymatic reaction decreases in the microwave field, which is one of the reasons that give an increase in the initial reaction rate ${ }_{[7]}$.

From the readings, it is estimated that initially the rise in temperature is more when compared with the latter part of experiment. This behavior may be due to the change in dielectric constant. Di-electric properties are functions of both frequency and temperature, and also these properties are heavily influenced by variables such as moisture content, density, etc. as the temperature increases, the moisture content of oil decreases. This accounts for the slower rise in temperature in the final phase of the experiment ${ }_{[6]}$.

The analysis done so far for coconut oil is repeated for water, which can be used as a reference for the values obtained with coconut oil.

\subsection{Power absorbed by water for volume $(50 \mathrm{ml})$, and magnetron input voltage $230 \mathrm{~V}$ at varying time periods.}

Mass of $50 \mathrm{ml}$ of water $\left(\mathrm{M}_{1}\right)-44.024 \mathrm{~g}$

Specific heat of water $\left(\mathrm{C}_{\mathrm{pl}}\right)-4.187 \mathrm{KJ} / \mathrm{kgK}_{[3]}$

Table 10. Power analysis of $50 \mathrm{ml}$ of water as load at $230 \mathrm{~V}$ with heating time, $t=60$ seconds.

\begin{tabular}{|c|c|c|c|c|}
\hline $\begin{array}{c}\text { Sl } \\
\text { no. }\end{array}$ & $\begin{array}{c}\text { initial temp } \\
(\mathrm{C})\end{array}$ & $\begin{array}{c}\text { final temp } \\
(\mathrm{C})\end{array}$ & $\Delta \mathrm{T}(\mathrm{C})$ & $\begin{array}{c}\text { power in } \\
\text { watts }\end{array}$ \\
\hline 1 & 30 & 70 & 40 & 167.66 \\
\hline 2 & 30 & 66 & 36 & 150.89 \\
\hline 3 & 30 & 68 & 38 & 159.27 \\
\hline 4 & 30 & 65 & 35 & 146.7 \\
\hline 5 & 30 & 66 & 36 & 150.89 \\
\hline \multicolumn{4}{|c|}{ Average Power } & $\mathbf{1 5 5 . 0 8}$ \\
\hline
\end{tabular}


Table11. Power analysis of $50 \mathrm{ml}$ of water as load at $230 \mathrm{~V}$ with heating time, $t=90$ seconds.

\begin{tabular}{|c|c|c|c|c|}
\hline $\begin{array}{c}\text { Sl } \\
\text { no. }\end{array}$ & $\begin{array}{c}\text { initial temp } \\
(\mathrm{C})\end{array}$ & $\begin{array}{c}\text { final temp } \\
(\mathrm{C})\end{array}$ & $\Delta \mathrm{T}(\mathrm{C})$ & $\begin{array}{c}\text { power in } \\
\text { watts }\end{array}$ \\
\hline 1 & 30 & 83 & 53 & 148.1 \\
\hline 2 & 30 & 83 & 53 & 148.1 \\
\hline 3 & 30 & 82.5 & 52.5 & 146.7 \\
\hline 4 & 30 & 82 & 52 & 145.3 \\
\hline 5 & 30 & 83 & 53 & 148.1 \\
\hline \multicolumn{4}{|c|}{ Average Power } & $\mathbf{1 4 7 . 2 6}$ \\
\hline
\end{tabular}

Table12. Power analysis of $50 \mathrm{ml}$ of water as load at $230 \mathrm{~V}$ with heating time, $t=120$ seconds.

\begin{tabular}{|c|c|c|c|c|}
\hline $\begin{array}{c}\text { Sl } \\
\text { no. }\end{array}$ & $\begin{array}{c}\text { initial } \\
\text { temp }(\mathrm{C})\end{array}$ & $\begin{array}{c}\text { final temp } \\
(\mathrm{C})\end{array}$ & $\begin{array}{c}\Delta \mathrm{T} \\
(\mathrm{C})\end{array}$ & $\begin{array}{c}\text { power in } \\
\text { watts }\end{array}$ \\
\hline 1 & 30 & 97 & 67 & 140.41 \\
\hline 2 & 30 & 95 & 65 & 136.22 \\
\hline 3 & 30 & 98 & 65 & 136.22 \\
\hline 4 & 30 & 98 & 68 & 142.51 \\
\hline 5 & 30 & 98 & 68 & 142.51 \\
\hline \multicolumn{4}{|c|}{ Average Power } & $\mathbf{1 3 9 . 5 8}$ \\
\hline
\end{tabular}

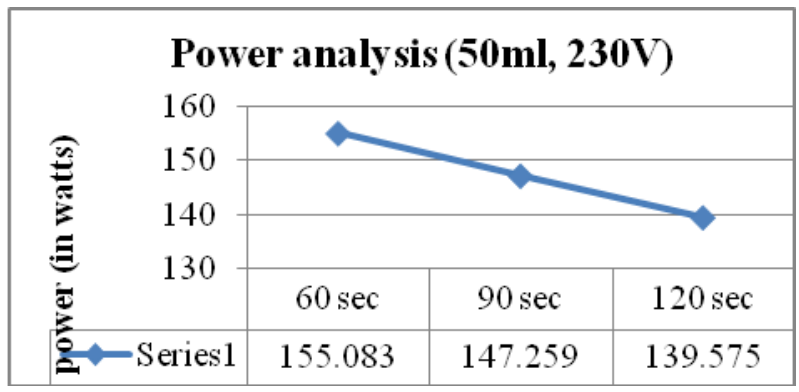

Fig.4 shows the average power analysis graph for water $(50 \mathrm{ml})$ at $230 \mathrm{~V}$ with variable time periods.

Table 13. comparison between the power analysis $(50 \mathrm{ml}$, $230 \mathrm{~V}$ ) of water and coconut oil.

\begin{tabular}{|c|c|c|}
\hline Time(s) & Power(water) & Power(coconut oil) \\
\hline $60 \mathrm{~s}$ & 155.08 & 100.77 \\
\hline $90 \mathrm{~s}$ & 147.26 & 78.94 \\
\hline $120 \mathrm{~s}$ & 139.58 & 71.511 \\
\hline
\end{tabular}

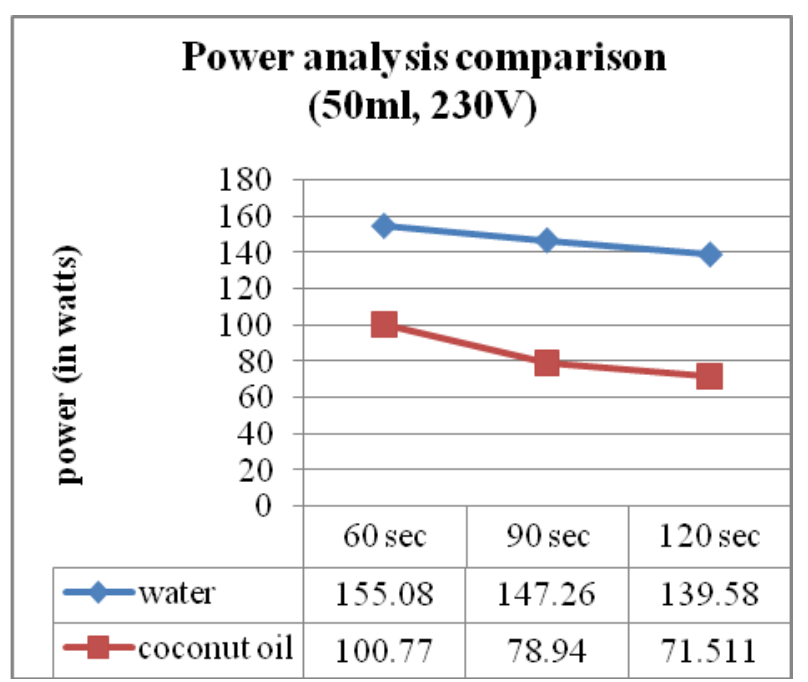

Fig.5 shows the comparison graph for the same.

From the fig.5, the comparison graph, the power absorbed by coconut oil is found to be lower compared to that of water. As the time interval increases, a linear relation is observed between the power absorption characteristics of oil and water. The power absorbed by coconut oil is found to be $65 \%, 54 \%$ and $51 \%$ for time duration of $60 \mathrm{~s}, 90 \mathrm{~s}$, and $120 \mathrm{~s}$ respectively when compared with water. This linear relation is justified by the fact that as the temperature increases, the moisture content of the oil decreases and this results in the reduction of dielectric constant. This accounts for the reduction in power absorption of the coconut oil as the time duration is increased.

\subsection{Power absorbed with heating load as water for 60 seconds, at $230 \mathrm{~V}$ for varying volume.}

Weight of $50 \mathrm{ml}$ of water $\left(\mathrm{M}_{11}\right)-44.024 \mathrm{~g}$

Weight of $100 \mathrm{ml}$ of water $\left(\mathrm{M}_{12}\right)-88.048 \mathrm{~g}$

Weight of $150 \mathrm{ml}$ of water $\left(\mathrm{M}_{13}\right)-132.072 \mathrm{~g}$

Specific heat of water $\left(\mathrm{C}_{\mathrm{pl}}\right)-4.187 \mathrm{KJ} / \mathrm{kgK}$

Table14. Power analysis of $50 \mathrm{ml}\left(\mathrm{M}_{11}\right)$ of water as load at $230 \mathrm{~V}$ with heating time, $\mathrm{t}=60$ seconds.

\begin{tabular}{|c|c|c|c|c|}
\hline $\begin{array}{l}\text { Sl } \\
\text { no. }\end{array}$ & $\begin{array}{l}\text { initial temp } \\
\text { (C) }\end{array}$ & $\begin{array}{l}\text { final temp } \\
\text { (C) }\end{array}$ & $\Delta \mathrm{T}(\mathrm{C})$ & $\begin{array}{c}\text { power in } \\
\text { watts }\end{array}$ \\
\hline 1 & 30 & 70 & 40 & 167.66 \\
\hline 2 & 30 & 66 & 36 & 150.89 \\
\hline 3 & 30 & 68 & 38 & 159.27 \\
\hline 4 & 30 & 65 & 35 & 146.7 \\
\hline 5 & 30 & 65 & 35 & 146.7 \\
\hline & & \multicolumn{2}{|c|}{ Average Power } & 154.24 \\
\hline
\end{tabular}


Table 15. Power analysis of $100 \mathrm{ml}\left(\mathrm{M}_{12}\right)$ of water as load at $230 \mathrm{~V}$ with heating time, $t=60$ seconds.

\begin{tabular}{|c|c|c|c|c|}
\hline $\begin{array}{l}\text { Sl } \\
\text { no. }\end{array}$ & $\begin{array}{l}\text { initial temp } \\
\text { (C) }\end{array}$ & $\begin{array}{l}\text { final temp } \\
\text { (C) }\end{array}$ & $\Delta \mathrm{T}(\mathrm{C})$ & $\begin{array}{c}\text { power in } \\
\text { watts }\end{array}$ \\
\hline 1 & 30 & 63 & 33 & 239.7 \\
\hline 2 & 30 & 60 & 30 & 217.91 \\
\hline 3 & 30 & 62 & 32 & 232.43 \\
\hline 4 & 30 & 62 & 32 & 232.43 \\
\hline 5 & 30 & 60 & 30 & 217.91 \\
\hline & & \multicolumn{2}{|c|}{ Average Power } & 228.08 \\
\hline
\end{tabular}

Table.16 Power analysis of $150 \mathrm{ml}\left(\mathrm{M}_{13}\right)$ of water as load at $230 \mathrm{~V}$ with heating time, $t=60$ seconds.

\begin{tabular}{|c|c|c|c|c|}
\hline $\begin{array}{c}\text { Sl } \\
\text { no. }\end{array}$ & $\begin{array}{c}\text { initial } \\
\text { temp }(\mathrm{C})\end{array}$ & $\begin{array}{c}\text { final temp } \\
(\mathrm{C})\end{array}$ & $\Delta \mathrm{T}(\mathrm{C})$ & power in watts \\
\hline 1 & 30 & 58 & 28 & 289.4 \\
\hline 2 & 30 & 57 & 27 & 279.06 \\
\hline 3 & 30 & 57 & 27 & 279.06 \\
\hline 4 & 30 & 56 & 26 & 268.73 \\
\hline 5 & 30 & 57 & 27 & 279.06 \\
\hline & \multicolumn{5}{|c|}{ Average Power } & $\mathbf{2 7 9 . 0 6}$ \\
\hline
\end{tabular}

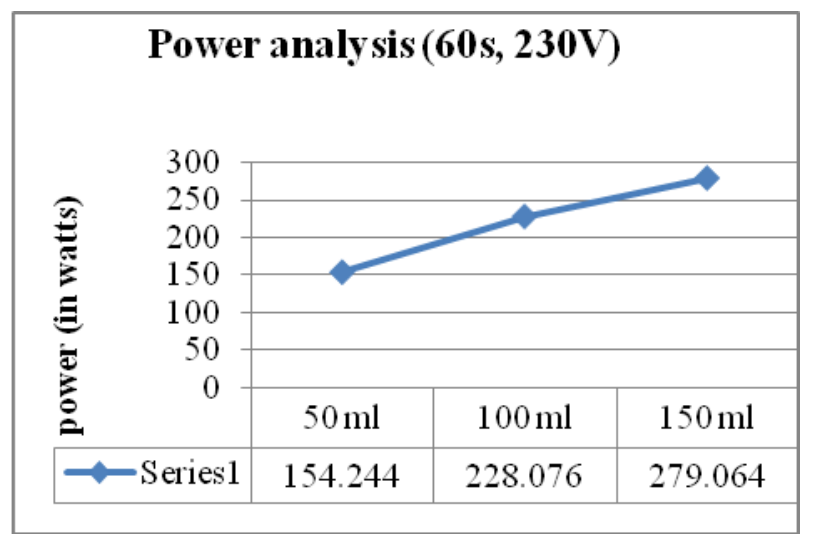

Fig6: shows the average power analysis graph for water as heating load at 230 Vfor 60 seconds with variable volume.

Table 17: gives the comparison between the power analysis $(60 \mathrm{~s}, 230 \mathrm{~V})$ of water and coconut oil.

\begin{tabular}{|c|c|c|}
\hline Volume & Power(water) & Power(coconut oil) \\
\hline $50 \mathrm{ml}$ & 154.24 & 100.77 \\
\hline $100 \mathrm{ml}$ & 228.08 & 123 \\
\hline $150 \mathrm{ml}$ & 279.06 & 140.86 \\
\hline
\end{tabular}

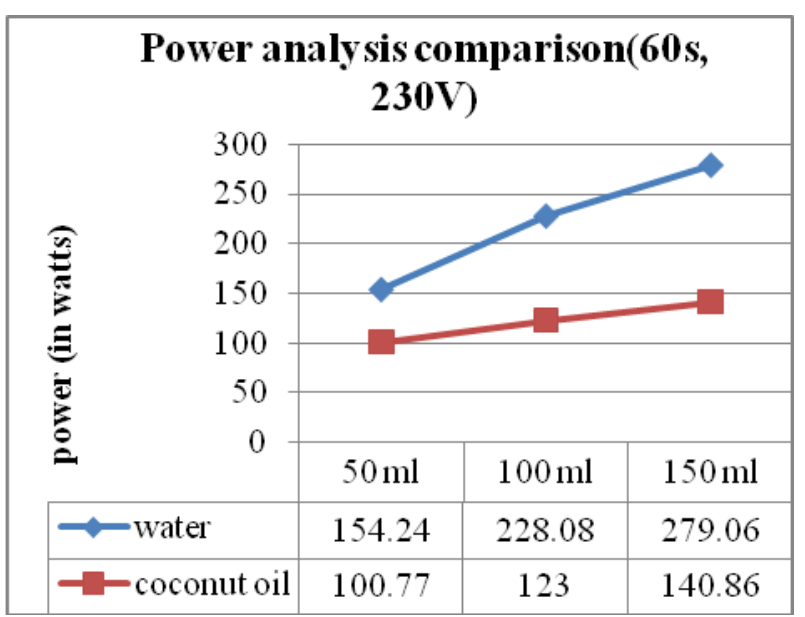

Fig.7 shows the comparison graph for the same.

As explained above, the same linearization can be observed in this graph. However, the volume of the oil is varied with respect to time. Even though the power absorption characteristics are also affected by the change in volume, the change in di-electric constants is predominant in the temperature range that is considered. Hence the power absorbed decreases $[3]$.

\subsection{Power absorbed with heating load as water $(100 \mathrm{ml}, 60$ seconds) for varying magnetron voltages.}

Weight of $100 \mathrm{ml}$ of water $\left(\mathrm{M}_{1}\right)-88.048 \mathrm{~g}$

Specific heat of water $\left(\mathrm{C}_{\mathrm{pl}}\right)-4.187 \mathrm{KJ} / \mathrm{kgK}$

Table18. Power analysis of $100 \mathrm{ml}$ of water as load with heating time, $t=60$ seconds at $180 \mathrm{~V}$.

\begin{tabular}{|c|c|c|c|c|}
\hline $\begin{array}{l}\text { Sl } \\
\text { no. }\end{array}$ & $\begin{array}{l}\text { initial temp } \\
\text { (C) }\end{array}$ & $\begin{array}{l}\text { final temp } \\
\text { (C) }\end{array}$ & $\Delta \mathrm{T}(\mathrm{C})$ & $\begin{array}{c}\text { power in } \\
\text { watts }\end{array}$ \\
\hline 1 & 30 & 45.5 & 15.5 & 112.59 \\
\hline 2 & 30 & 44.5 & 14.5 & 105.32 \\
\hline 3 & 30 & 44.5 & 14.5 & 105.32 \\
\hline 4 & 30 & 43 & 13 & 94.426 \\
\hline 5 & 30 & 45 & 15 & 108.95 \\
\hline & & \multicolumn{2}{|c|}{ Average Power } & 105.32 \\
\hline
\end{tabular}

Table.19 Power analysis of $100 \mathrm{ml}$ of water as load with heating time, $t=60$ seconds at $200 \mathrm{~V}$.

\begin{tabular}{|c|c|c|c|c|}
\hline $\begin{array}{l}\text { S1 } \\
\text { no. }\end{array}$ & $\begin{array}{l}\text { initial temp } \\
\text { (C) }\end{array}$ & $\begin{array}{c}\text { final temp } \\
\text { (C) }\end{array}$ & $\Delta \mathrm{T}(\mathrm{C})$ & $\begin{array}{c}\text { power in } \\
\text { watts }\end{array}$ \\
\hline 1 & 30 & 57 & 27 & 196.12 \\
\hline 2 & 30 & 57 & 27 & 196.12 \\
\hline 3 & 30 & 57 & 27 & 196.12 \\
\hline 4 & 30 & 57 & 27 & 196.12 \\
\hline 5 & 30 & 57 & 27 & 196.12 \\
\hline & & \multicolumn{2}{|c|}{ Average Power } & 196.12 \\
\hline
\end{tabular}


Table.20 Power analysis of $100 \mathrm{ml}$ of water as load with heating time, $t=60$ seconds at $220 \mathrm{~V}$.

\begin{tabular}{|c|c|c|c|c|}
\hline $\begin{array}{l}\text { Sl } \\
\text { no. }\end{array}$ & $\begin{array}{l}\text { initial temp } \\
\text { (C) }\end{array}$ & $\begin{array}{l}\text { final temp } \\
\text { (C) }\end{array}$ & $\Delta \mathrm{T}(\mathrm{C})$ & $\begin{array}{c}\text { power in } \\
\text { watts }\end{array}$ \\
\hline 1 & 30 & 63.5 & 33.5 & 243.33 \\
\hline 2 & 30 & 64.5 & 34.5 & 250.59 \\
\hline 3 & 30 & 64.5 & 34.5 & 250.59 \\
\hline 4 & 30 & 65 & 35 & 254.23 \\
\hline 5 & 30 & 64.5 & 34.5 & 250.59 \\
\hline & & \multicolumn{2}{|c|}{ Average Power } & 249.87 \\
\hline
\end{tabular}

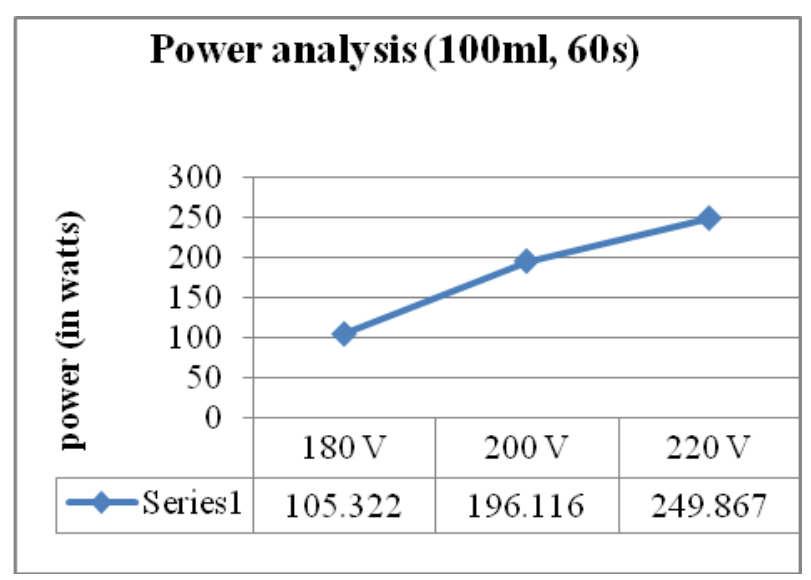

Fig8.Shows the average power analysis graph for water $(100 \mathrm{ml})$ as heating load for 60 seconds with variable magnetron voltages.

Table 21. Gives the comparison between the power analysis $(100 \mathrm{ml}, 60 \mathrm{~s})$ of water and coconut oil.

\begin{tabular}{|c|c|c|}
\hline Voltage & Power(water) & Power(coconut oil) \\
\hline $180 \mathrm{~V}$ & 105.32 & 67.313 \\
\hline $200 \mathrm{~V}$ & 196.12 & 108.55 \\
\hline $220 \mathrm{~V}$ & 249.87 & 125.46 \\
\hline
\end{tabular}

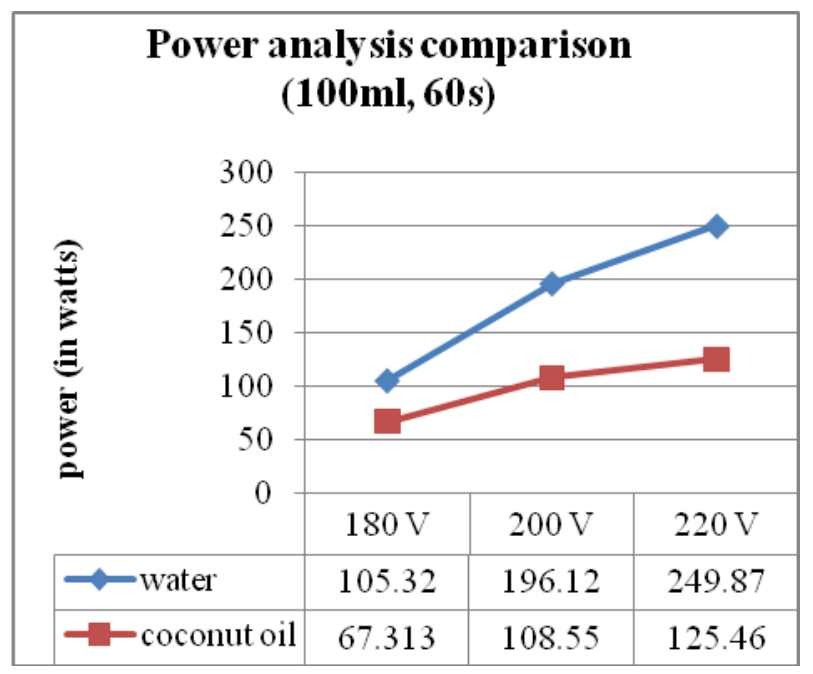

Fig.9 shows the comparison graph for the same.
Here the input voltage of microwave oven is varied keeping the other parameters constant. The specific heat capacity of coconut oil is lower when compared to water.This can also account for the lower power absorbed by coconut oil compared to that of water.

\section{CONCLUSION}

Microwave plasma deposition is found to be very effective, economic and power saving. But the interaction of microwaves is found to be different for different loads and position of the load in oven cavity. Also there exists a difference between rated and absorbed power. Moreover, efficiencies of small quantities of load complicate the prediction of course of heating (time for heating of certain) in certain ovens. Apart from volume, the di-electric constant too has great effect on heating.

A quantitative power analysis is thus necessary before plasma deposition of thin film can be carried out effectively. The power analysis was carried out using coconut oil as heating load and a reference load as water. The efficiency was found to be lower in case of coconut oil when compared to water. The power absorbed by coconut oil lied in the range $70-140$ watts while that of water being $100-280$ watts. Thermal characteristics were plotted for varying load magnetron voltage and period of heating. So with further analysis with different loads, the power delivered by the oven and power absorbed by the load, and hence the efficiency of the microwave oven can be determined. Also we can conclude that vegetable oils can be used as a suitable substituent for mineral oils for lubrication purposes where the lubricant is also required to provide the transfer of heat.

\section{REFERENCES}

[1] Ricardo Malheiro, Susana Casal, Elsa Ramalhosa, Jose Alberto Perera, "Microwave heating: a time saving technology or a way induce vegetable oil oxidation?" Polytechnic institute of Braganca, Portugal.

[2] Gopala Krishna A.G., Gaurav Raj, Ajit Singh Bhatnagar, Prasanth Kumar P K, PreethyChandrashekhar, "coconut oil: chemistry, production and its applications- a review" , Department of lipid science and traditional foods, Central food technological research institute (CSIR), Mysore.

[3] JiriniaHousova and KarelHoke, "microwave heating: the influence of oven and load parameters on the power absorbed in the heated load", Food research institute of Paraguay, Czech Republic.

[4] Alexander Irzh, IsascharGenish, "Synthesis of $\mathrm{ZnO}$ and $\mathrm{Zn}$ nano particles in microwave plasma and their deposition on glass slides", Langmuir 2010,26(8),59765984

[5] Charles F Hill, "Temperature limits set by oil and cellulose insulation", paper no: 39-63, recommended by AIEE committee on power transmission and distribution, and presented at the AIEE winter convention, New York.

[6] Prof. T S Tan, "Microwave heating of oil- palm fresh fruit samples", Department of electrical engineering, University of Malaya, Malaysia.

[7] N Saifuddeen, L Wei Zhan, K XinNing, "Heat modeling of microwave assisted epoxidation of palm-acid oil", department of engineering sciences, college of engineering, Malaysia. 
[8] Y. Bertrand and L. C. Hoang, "Vegetable oil as a substitute for mineral oils", Proceedings of the 7th International Conference on Properties and Applications of Dielectric Materials, June 1-5, 2003, Nagoya

[9] Mohamed G. Megahed, "Effect of microwave heating of linseed oil on the formation of primary and secondary oxidation products", Agricultural and Biology Journal of North America, 2011.

[10] Jittrepotch N, Kongbangkerd T and Rojsuntornkitti K, "Influence of microwave irradiation on lipid oxidation and acceptance in peanut (Arachis hypogaea L) seeds", Department of Agro-Industry, Thailand, International Food Research Journal 17: 173-179 (2010).
[11] Minar M. Hassanein, Safinaz M. El-Shami and M. Hassan El-Mallah, "Changes occurring in vegetable oils composition due to microwave heating", National Research Centre, Fats and Oils Dept., Dokki, Cairo, Egypt.

[12] S. Yamamoto, K. Kato, F. Endo, Y. Hatta, H. Koide and H. Okubo, "Kerr Electro-Optic Field Measurement in Palm Oil Fatty Acid Ester Transformer Insulation System", 2007 Annual Report Conference on Electrical Insulation and Dielectric Phenomena.

[13] V.K. Khanna, "Nanoparticle-based Sensors", Central Electronics Engineering Research Institute, Pilani. 